\title{
Proceeding
}

Supplementary Issue: Autumn Conferences of Sports Science. Costa Blanca Sports Science Events, 18-19 December 2020. Alicante, Spain.

\section{Effects of black Berberis vulgaris $L$ combined with aerobic and resistance exercise on blood metabolic parameters and liver enzymes in obese rats}

\author{
SARA TORKAMANEH ${ }^{1}$, JAVIER GENE-MORALES ${ }^{1,2}$, ALVARO JUESAS ${ }^{1}$, JORGE FLÁNDEZ ${ }^{3}$, RAOUF \\ HAMMAMI ${ }^{4}$, MAHMOUD RAFIEIAN-KOPAEI ${ }^{5} \triangle$, JUAN CARLOS COLADO 1,6 \\ ${ }^{1}$ Research Unit in Sport and Health, University of Valencia, Valencia, Spain \\ 2Institute on Traffic and Road Safety (INTRAS), University of Valencia, Valencia, Spain \\ 3 Institute of Education Sciences, Austral University of Chile, Ciudad de Valdivia, Chile \\ ${ }^{4}$ Higher Institute of Sport and Physical Education of Ksar-Said, University of La Manouba, Tunis, Tunisia \\ ${ }^{5}$ Medical Plants Research Center, Shahrekord Univesity of Medical Sciences, Sharekord, Islamic Republic of Iran \\ ${ }^{6}$ Department of Physical Education and Sports, University of Valencia, Valencia, Spain
}

\begin{abstract}
Purpose: The aim of this study was to investigate the effects of a six-week intake of Berberis vulgaris $L$ in combination with resistance and aerobic exercise on the lipid profile, metabolic parameters, and liver enzymes of obese male rats. Methods: 56 male Wistar rats were divided into seven groups: 1) healthy control $(n=8) ; 2)$ hypercaloric fatty-food-based diet $(n=8) ; 3)$ aerobic exercise (AE, $n=8) ; 4)$ resistance exercise $(R E, n=8) ; 5)$ black Berberis vulgaris $L$ extract intake $(n=8)$; 6) Berberis intake combined with aerobic exercise (BAE, $n=8)$; and 7) Berberis intake combined with resistance exercise (BRE, $n=8)$. All the rats (except the controls) were induced fatty liver by six weeks of a hypercaloric diet before the intervention. After six weeks of intervention, blood samples were taken to obtain cholesterol, triglycerides, high-density lipoprotein cholesterol (HDL), low-density lipoprotein cholesterol (LDL), glucose of c-reactive protein (CRP), alanine aminotransferase (ALT), aspartate aminotransferase (AST), and urea. Differences between groups were evaluated using the Kruskal Wallis test with post-hoc pairwise comparisons. Results: All the intervention groups significantly $(p<.05)$ improved the parameters compared to the hypercaloric group in almost all the assessed parameters, reaching in many cases significantly better values than the healthy group (control). Similar results were obtained between the experimental groups; however, the outcomes were slightly better (non-significant differences) for the combination of the Berberis extract and both exercise methodologies. Conclusion: The use of herbal medicines such as Berberis vulgaris $L$ in combination with aerobic or resistance exercises may be useful in the prevention of cardiovascular disease by improving risk factors such as blood lipid levels.
\end{abstract}

Keywords: Aerobic; Resistance training; Physical activity; Fatty liver; Cardiovascular disease; Wistar rats.

\section{Cite this article as:}

Torkamaneh, S., Gene-Morales, J., Juesas, A., Flández, J., Hammami, R., Rafieian-Kopaei, M., \& Colado, J.C. (2021). Effects of black Berberis vulgaris $L$ combined with aerobic and resistance exercise on blood metabolic parameters and liver enzymes in obese rats. Journal of Human Sport and Exercise, 16(2proc), S619-S629. doi:https://doi.org/10.14198/ihse.2021.16.Proc2.47

Corresponding author. Medical Plants Research Centre, Basic Health Science Institute, Shahrekord University of Medical Science. 8813833435, Sharekord, Islamic Republic of Iran. https://orcid.org/0000-0002-1860-1141

E-mail: rafieian@skums.ac.ir

Abstract submitted to: Autumn Conferences of Sports Science. Costa Blanca Sports Science Events, 18-19 December 2020. Alicante, Spain.

JOURNAL OF HUMAN SPORT \& EXERCISE ISSN 1988-5202

(C) Faculty of Education. University of Alicante

doi:10.14198/jhse.2021.16.Proc2.47 


\section{INTRODUCTION}

According to the latest report from American Heart Association, cardiovascular disease (CVD) is one of the leading causes of mortality worldwide, accounting for $30 \%$ of deaths caused annually (Mazidi \& Speakman, 2018). Obesity and overweight are among the most important risk factors for CVD. Previous studies have reported that mortality from CVD is more than three times higher in obese people than in normal-weight people (Aslani et al., 2016). Excessive adipose tissue increases obesity, overweight, and also CVD risk factors (Atkins et al., 2014). Increasing liver enzymes as a result of obesity and overweight may lead to liver cirrhosis and hepatocellular carcinoma associated with non-alcoholic fatty liver disease (NAFLD) (Maliakkal, 2020).

Due to these facts, it is necessary to continue the efforts to control NAFLD and CVD risk factors such as obesity and overweight (Liu et al., 2019). Low concentration of high-density lipoprotein (HDL) and high levels of total cholesterol, triglycerides, very-low-density lipoprotein, low-density lipoprotein (LDL), and increased body mass index (BMI) are associated with CVD (Yang et al., 2011). One of the best ways to reduce obesity and control blood lipoproteins is a proper diet and regular exercise (Wood et al., 1991; Shamsoddini et al., 2015). The use of medicinal herbs is one of the new approaches in the treatment of many diseases (Zhan et al., 2017). Diet, lifestyle, and genetic and environmental factors can increase obesity and chronic diseases. Behavioural interventions and healthy lifestyles are the best ways to lose weight; however, lifestyle changes could be difficult and challenging for many obese people (Haselgrübler et al., 2019). Over the years, many strategies such as drug treatments have been used to lose weight and control obesity. However, several antiobesity drugs have serious adverse effects such as anxiety, depression, and increased CVD risk. Therefore, some medicinal herbs could be used as an alternative strategy to manage obesity with less toxic side effects than chemical medicine (Haselgrübler et al., 2019; Kang \& Park, 2012).

One of these herbs with antioxidant properties is Berberis vulgaris $L$, a shrub of the genus Berberis, which is mainly cultivated in the region of South Khorasan in Iran and is one of the few plants whose root, peel, stem, leaves, flower, and fruits are used for various nutritive and medicinal purposes (Taheri et al., 2012). This plant is cultivated in many regions of the world and has a long history of use in traditional medicine (Dulić et al., 2019; Tabeshpour et al., 2017). Some of the alkaloids in black barberry when chemically analysed include berberine, palmatine, oxyaconthine, and berbamine, having each medicinal benefit. Berberine, the most significant compound of all, has a plethora of therapeutic benefits, including antibacterial, anti-tumoral, and anti-inflammatory properties, ameliorative effect on neural disorders, and preventive effect in coronary artery disease (Cao et al., 2020; Imenshahidi et al., 2019; Zarei et al., 2015).

On the other hand, recent reviews and meta-analyses have shown that physical exercise (both aerobic and resistance) has a significant effect on CVD (MacDonald et al., 2016). It has also been shown to reduce cardiac morbidity by $5 \%$, stroke by $8-14 \%$, and all-cause mortality by $4 \%$ in the average population (Schroeder et al., 2019). Improving metabolically active lean muscle mass is important for improving glucose metabolism (Kamada et al., 2017; Yang et al., 2014). Short-term randomized trials reported that resistance training reduces weight and also plays a role in improving CVD risk factors such as lipid profile (Miyachi, 2013). According to the current physical activity guidelines, it is recommended to perform resistance and aerobic exercises more than two times per week (Kamada et al., 2017; World Health Organization, 2017). Therefore, physical exercise is considered effective in weight loss and maintaining a reduced weight (Wang $\& X u, 2017)$. They may also be effective in reducing lipid aggregation in fatty liver disease. Exercise leads to increased functional levels of glucagon (a stimulant for glucose production pathways) in the liver. The increased functional level of glucagon caused by exercise can lead to changes in the expression of this 
particular gene corresponding to increased fat oxidation (Bernhardt et al., 2016; Torkamaneh et al., 2016). Exercise leads to a decrease in body fat levels and leads to long-term improvement in fatty liver disease. The combination of herbs having antioxidant properties and some exercises could likely reduce cardiovascular risk factors.

Therefore, the present study aimed to investigate the effects of a six-week daily intake of black Berberis vulgaris $L$, physical exercise (aerobic and resistance training), and their combination on the lipid profile (triglycerides, HDL, LDL, cholesterol), metabolic parameters (glucose, creatinine, c-reactive protein [CRP], urea), and liver enzymes (alanine aminotransferase [ALT], aspartate aminotransferase [AST]) in obese male rats. We hypothesized that the combination of physical exercise and black Berberis vulgaris $L$ extract will improve to a greater extent the assessed parameters, with no big difference between the aerobic and resistance exercise.

\section{MATERIAL AND METHODS}

\section{Participants}

In this study, 56 male Wistar rats (age: six weeks; average weight: $200 \mathrm{~g})$ were selected and divided into seven groups: 1) control following a normocaloric diet and no treatment $(n=8) ; 2)$ hypercaloric $(n=8)$ following a fatty-food-based diet and no treatment; 3 ) aerobic exercise ( $A E, n=8) ; 4$ ) resistance exercise (RE, $n=8) ; 5)$ ingestion of black Berberis vulgaris $L$ extract $(B, n=8) ; 6)$ ingestion of Black Berberis in combination with aerobic exercise (BAE, $n=8$ ); and 7 ) ingestion of Black Berberis in combination with resistance exercise (BRE, $n=8)$. All the groups were homogeneous in terms of number, breed, age, and weight. All ethical considerations and working protocols of this study were approved by Shahrekord's committee for monitoring Laboratory Animal Rights in Medical Sciences University with code 2-1-94.

The rats were kept for 12 weeks in the Shahrekord University Animal Laboratory Medical Sciences at a temperature between 22 and $27^{\circ} \mathrm{C}$. The room was illuminated in a controlled manner (12 hours off and 12 hours on). Six weeks were used to induce hyperlipidemia and hypercholesterolemia in the rats and six weeks to carry out the intervention. The hypercaloric, $A E, R E, B, B A E$, and BRE groups $(n=48)$ were induced with hyperlipidemia and hypercholesterolemia by diet (see below "Diet formulation" section) and 8 control rats remained healthy following a normocaloric diet.

\section{Intervention}

Diet formulation

During the six weeks before the intervention, Persintra-M emulsion was included in the diet of the 48 selected rats to induce them with hyperlipidemia. This emulsion was prepared from egg yolk and contained $1 \mathrm{~g}$ of cholesterol, palm oil of $80 \%$ purity, and intralipid liquid per $100 \mathrm{~g}$ of egg yolk. To produce hypercholesterolemia, $25 \mathrm{mg}$ of cholesterol were concentrated on $2 \mathrm{ml}$ and daily administered to the rats. In addition, palm oil, sugar, and cow fat were added to the rat's meal to bring it to $1 \%$ cholesterol and $20 \%$ sugar.

During the intervention period (six weeks) only the hypercaloric group continued with the above explained hypercaloric diet and the rest of the groups switched to a normocaloric animal diet. The controls remained all the 12 weeks with a normocaloric diet. Food and water was freely available to all the rats throughout the study. 


\section{Aerobic training program}

The six-week (three sessions per week) aerobic training program was performed on a treadmill and was divided into three phases (two weeks of adaptation, two weeks of overload, and two weeks of maintenance/consolidation). A familiarization period was carried out before the aerobic training program (see Table 1) to familiarize the rats with the materials and the procedures. All the phases used no inclination $\left(0^{\circ}\right)$. A 5-minute walk at $10 \mathrm{~m} / \mathrm{min}$ was used as a warm-up and cool-down in every session. The control group walked five minutes once per week at $10 \mathrm{~m} / \mathrm{min}$ and $0^{\circ}$ during the six weeks of the intervention.

To stimulate the rats to walk, an auditory stimulus (tapping on the wall of the treadmill) was used. For this purpose, a low-voltage electrical stimulus was initially used together with an audio stimulus. After the rats were conditioned to two stimuli simultaneously, the single audio stimulus was used in later sessions to comply with the ethics of animal experimentation.

Table 1. Aerobic training program.

\begin{tabular}{|c|c|c|c|c|c|c|}
\hline & \multicolumn{2}{|c|}{ Adaptation phase } & \multicolumn{2}{|c|}{ Overload phase } & \multicolumn{2}{|c|}{ Maintenance phase } \\
\hline & First week & Second week & Third week & Fourth week & Fifth week & Sixth week \\
\hline Speed & $8 \mathrm{~m} / \mathrm{min}$ & $12 \mathrm{~m} / \mathrm{min}$ & $18 \mathrm{~m} / \mathrm{min}$ & $20 \mathrm{~m} / \mathrm{min}$ & $20 \mathrm{~m} / \mathrm{min}$ & $20 \mathrm{~m} / \mathrm{min}$ \\
\hline Time & $10 \mathrm{~min}$ & $20 \mathrm{~min}$ & $30 \mathrm{~min}$ & $40 \mathrm{~min}$ & $40 \mathrm{~min}$ & $40 \mathrm{~min}$ \\
\hline
\end{tabular}

Resistance exercise

A one-meter ladder with 50 steps separated by $2 \mathrm{~cm}$, a width of $50 \mathrm{~cm}$, and an inclination of $85^{\circ}$ was used for the resistance training. A load pouch attached to the proximal portion of the rats' tail $11-2 \mathrm{~cm}$ after the hair growth point) was used as resistance. Prior to the six weeks of the resistance training program, a familiarization period without external weight was carried out. The number of repetitions of the training program (see Table 2) in each session ranged from 8 to 12 repetitions, with a two-minute rest in between; each repetition had to be completed in 8 seconds. At the beginning and end of the exercise, 5 repetitions without weight were used as a warm-up and cool-down. The rats were placed at the bottom of the ladder and were motivated to climb the ladder by gently pushing on their backside. No rewards or abnormal stimuli such as electrical stimulation, cold water, or air pressure were used in this study.

Table 2. Resistance training program.

\begin{tabular}{lcccccc}
\hline & \multicolumn{2}{c}{ Adaptation phase } & \multicolumn{2}{c}{ Overload phase } & \multicolumn{2}{c}{ Maintenance phase } \\
\hline & First & Second & Third & Fourth & Fifth & Sixth \\
& week & week & week & week & week & week \\
\hline Rats' weight average & $240 \mathrm{~g}$ & $252 \mathrm{~g}$ & $260 \mathrm{~g}$ & $266 \mathrm{~g}$ & $277 \mathrm{~g}$ & $287 \mathrm{~g}$ \\
$\begin{array}{l}\text { Ratio overload per } \\
\text { bodyweight }\end{array}$ & $50 \%$ & $75 \%$ & $85 \%$ & $95 \%$ & $110 \%$ & $120 \%$ \\
Average weight used & $120 \mathrm{~g}$ & $189 \mathrm{~g}$ & $221 \mathrm{~g}$ & $253 \mathrm{~g}$ & $305 \mathrm{~g}$ & $344 \mathrm{~g}$ \\
\hline
\end{tabular}

Black Berberis vulgaris $L$ extraction and use

Samples of black Berberis vulgaris $L$ extract were prepared and used after confirmation from the University's Center for Herbal Medicine Research. The Berberis root was pulverized using a mechanical mill (Moulinex, Osaka, Japan) and the powder was dissolved in 2 litres of $70 \%$ alcohol and $30 \%$ water. The solution was kept at laboratory temperature for 72 hours. It was then filtered and condensed in a rotary apparatus and kept in an incubator at a temperature of $37^{\circ} \mathrm{C}$ for three days. A dosage of $400 \mathrm{mg} / \mathrm{kg}$ was administered daily to the rats by gavage. 


\section{Measures}

After six weeks, blood samples were taken in a single session. The rats were anesthetized by intraperitoneal injection of ketamine $(70 \mathrm{mg} / \mathrm{kg})$ and xylazine $(3-5 \mathrm{mg} / \mathrm{kg})$. Blood samples were taken from the rats' hearts and placed in a Sigma centrifuge (Rontgen Co., Remscheid, Germany) at 5000 revolutions. The serum was separated using Pars Azmoon kits (Pars Azmoon Co., Tehran, Iran) and transferred to a BT3000 analyser (Biotecnica Instrument S.p.A., Rome, Italy). Values of the lipid profile (triglycerides, HDL, LDL, cholesterol), metabolic parameters (glucose, creatinine, CRP, urea), and liver enzymes (ALT, AST) were calculated.

\section{Data analysis}

After a basic data curation, the normality of the distribution and homogeneity of variances of each variable was assessed through the Shapiro-Wilk and Levene tests, respectively. None of the variables complied with normality and homoscedasticity assumption among the seven groups. Therefore, Kruskal Wallis testing was conducted. The effect size was reported as the eta squared $\left(\eta^{2}\right)$ where $0.01<\eta^{2}<0.06$ constitutes a small effect, $0.06 \leq \eta^{2} \leq 0.14$ a medium effect and $\eta^{2}>0.14$ constitutes a large effect. After this, paired post-hoc tests with no adjustment evaluated significant differences. A 95\% confidence level (significance $p<.05$ ) was accepted as statistically significant. Statistical analysis was carried out using commercial software IBM SPSS Statistics for Macintosh (Version 26.0; IBM Corp., Armonk, NY). All data are reported as the means \pm the standard deviations and the $95 \%$ confidence interval.

\section{RESULTS}

Twelve weeks of fatty food diet were enough to significantly worsen almost all the variables in the hypercaloric group compared to the controls. The Kruskal Wallis test indicated that significant differences existed among the groups in all the study variables, with AST: $H(6)=36.37, p<.001, \eta^{2}=0.62 ; A L T: H(6)=18.83, p=.004$, $\eta^{2}=0.26$; CRP: $H(6)=28.07, p<.001, \eta^{2}=0.45$; creatinine: $H(6)=35.51, p<.001, \eta^{2}=0.60 ;$ urea: $H(6)$ $=35.50, p<.001, \eta^{2}=0.60$; cholesterol: $H(6)=38.31, p<.001, \eta^{2}=0.66$; glucose: $H(6)=22.22, p=.001$, $\eta^{2}=0.33$; triglycerides: $\mathrm{H}(6)=20.62, p=.002, \eta^{2}=0.30 ; \mathrm{LDL}: \mathrm{H}(6)=28.10, p<.001, \eta^{2}=0.45 ; \mathrm{HDL}: \mathrm{H}(6)$ $=19.15, p=.004, \eta^{2}=0.27$. Tables 3 and 4 present the outcomes of the intervention in the liver enzymes and metabolic parameters.

\section{DISCUSSION}

The purpose of the present study was to analyse the effects of physical exercise (aerobic and resistance) in combination with black Berberis vulgaris $L$ extract on the blood parameters (lipid profile, liver enzymes, and metabolic parameters) of obese male rats. To assess this, a control group was kept healthy and the other six groups were fed with a hypercaloric diet for six weeks. After this period, one group continued with the hypercaloric diet and the other five switched to a normocaloric diet and different treatment programs (aerobic or resistance exercise, Berberis vulgaris $L$ extract intake, and aerobic or resistance exercise combined with the intake of Berberis vulgaris $L$ extract). The most noteworthy findings were that a six-week treatment program was enough to significantly $(p<.05)$ revert the negative values raised by the hypercaloric diet, showing all the treatments improvements in almost all the assessed variables. The combination of the exercise with the ingestion of the Berberis extract provided slightly better results, although the differences between the treatments were not significant, which partially supports the study hypothesis. Concerning the comparison between aerobic and resistance training in improving the assessed parameters, not many significant differences were encountered. It is worth highlighting that none of both training methodologies 
significantly improved the cholesterol after six weeks and that the aerobic training did not improve urea levels compared to the hypercaloric-diet group.

Table 3. Levels of liver enzymes (AST/GOT and ALT/GPT) and metabolic parameters (CRP, creatinine, and urea) in all experimental groups (all $n=8$ ).

\begin{tabular}{|c|c|c|c|c|c|}
\hline Group & AST & ALT & CRP & Creatinine & Urea \\
\hline & $93.50 \pm 9.94^{(3), 4,5,6,7}$ & $41.37 \pm 7.87$ & $16.55 \pm 1.47$ & $0.75 \pm 0.07^{3,4,5,6,7}$ & $36.00 \pm 5.50^{2,3,4}$ \\
\hline 1 & [85.18-101.81] & [34.82-47.92] & [15.31-17.78] & [0.68-0.81] & [31.35-40.46] \\
\hline \multirow{3}{*}{ (Control) } & Median: 97.50 & Median: 43.00 & Median: 17.10 & Median: 0.70 & Median: 34.50 \\
\hline & IQR: 17.25 & IQR: 10.50 & IQR: 0.85 & IQR: 0.10 & IQR: 8.00 \\
\hline & $155.62 \pm 28.373,4,5,6,7$ & $72.50 \pm 17.33^{*}$ & $22.93 \pm 0.96^{*}$ & $0.98 \pm 0.14^{3,4,5,6,7}$ & $59.50 \pm 14.66^{(4), 5,6,7}$ \\
\hline 2 & [131.89-179.35] & [58.00-86.99] & [22.12-23.17] & [0.86-1.10] & [47.23-71.76] \\
\hline \multirow[t]{3}{*}{ (Hyper) } & Median: 148.00 & Median: 66.50 & Median: 23.05 & Median: 1.00 & Median: 52.50 \\
\hline & IQR: 52.00 & IQR: 19.75 & IQR: 1.50 & IQR: 0.10 & IQR: 19.75 \\
\hline & $55.87 \pm 24.12$ & $48.62 \pm 15.81$ & $17.23 \pm 1.30(6)$ & $0.46 \pm 0.09$ & $47.75 \pm 3.65^{5,6,7}$ \\
\hline 3 & [35.70-76.04] & [35.39-61.85] & [16.14-18.32] & {$[0.38-0.53]$} & {$[44.69-50.80]$} \\
\hline \multirow[t]{3}{*}{$(\mathrm{AE})$} & Median: 51.50 & Median: 44.50 & Median: 17.25 & Median:0.50 & Median: 48.50 \\
\hline & IQR: 36.00 & IQR: 28.75 & IQR: 2.63 & IQR: 0.10 & IQR: 6.25 \\
\hline & $38.87 \pm 12.63$ & $50.00 \pm 8.51^{(6)}$ & $17.32 \pm 0.93^{(6)}$ & $0.48 \pm 0.08$ & $45.87 \pm 4.29(5), 6,7$ \\
\hline 4 & [28.31-49.43] & [42.87-57.12] & [16.54-18.10] & [0.41-0.55] & [42.28-49.46] \\
\hline \multirow[t]{3}{*}{ (RE) } & Median: 36.50 & Median: 49.50 & Median: 17.15 & Median: 0.50 & Median: 46.00 \\
\hline & IQR: 9.50 & IQR: 10.00 & IQR: 1.25 & IQR: 0.17 & IQR: 8.50 \\
\hline & $36.75 \pm 8.04$ & $49.50 \pm 14.18^{(6)}$ & $17.20 \pm 1.18^{(6)}$ & $0.46 \pm 0.05$ & $40.50 \pm 5.23$ \\
\hline 5 & [30.02-43.47] & [37.64-61.35] & [16.20-18.19] & {$[0.41-0.50]$} & [36.12-44.87] \\
\hline \multirow[t]{3}{*}{ (Berberis) } & Median: 36.00 & Median: 49.00 & Median: 17.30 & Median: 0.50 & Median: 42.50 \\
\hline & IQR: 14.25 & IQR: 27.75 & IQR: 1.40 & IQR: 0.10 & IQR: 7.75 \\
\hline & $35.75 \pm 5.14$ & $40.25 \pm 3.95$ & $15.87 \pm 0.90$ & $0.48 \pm 0.13$ & $37.50 \pm 3.89$ \\
\hline \multirow{4}{*}{$\begin{array}{c}6 \\
(\mathrm{BAE})\end{array}$} & [31.44-40.05] & [36.94-43.55] & [15.11-16.63] & {$[0.37-0.60]$} & [34.24-40.75] \\
\hline & Median: 38.00 & Median:40.50 & Median: 15.57 & Median: 0.45 & Median: 37.50 \\
\hline & IQR: 8.50 & IQR: 6.25 & IQR: 1.78 & IQR: 0.10 & IQR: 6.25 \\
\hline & $38.50 \pm 10.09$ & $44.88 \pm 16.39$ & $16.30 \pm 1.03$ & $0.45 \pm 0.09$ & $36.75 \pm 6.04$ \\
\hline \multirow{2}{*}{$\begin{array}{c}7 \\
\text { (BRE) }\end{array}$} & [30.05-46.96] & [31.17-58.59] & [15.43-17.16] & $0.52]$ & [31.69-41.80] \\
\hline & Median: 37.50 & Median: 46 & $\begin{array}{l}\text { Median: } 16.40 \\
\text { LR. } 175\end{array}$ & Median: 0.45 & Median: 34.50 \\
\hline
\end{tabular}

Data are presented as mean \pm standard deviation and $95 \%$ confidence interval for the mean [lower bound-upper bound]; median and interquartile range $(I Q R)$ are also displayed for the non-normal variables. Being *: significant difference $(p<.05)$ with all the rest of the groups; 1,2,3,4,5,6,7: significant difference with the group 1, 2, 3, 4, 5, 6, or 7, respectively (numbers between brackets represent statistical tendency at the level $0.5<p<1.3) ;$ IQR: interquartile range; Hyper: hypercaloric group; $A E$ : aerobic exercise group; RE: resistance exercise group; BAE: black Berberis vulgaris extract intake in combination with aerobic exercise; BRE: black Berberis vulgaris extract intake in combination with resistance exercise; AST: aspartate aminotransferase (also known as GOT); ALT: alanine aminotransferase (also known as GPT); CRP: C-reactive protein.

Supporting our results, Berberis vulgaris is recognized within the scientific body of knowledge as one of the functional foods that could be beneficial for the management of hyperlipidemia and chronic inflammation in humans, having a strong protective effect on the cardiovascular system (Changizi Ashtiyani et al., 2013; Emamat et al., 2020; Fatehi et al., 2005). Previous expert literature reported that the intake of Berberis vulgaris can reduce lipid profile and liver enzymes in serum (Changizi Ashtiyani et al., 2013; Emamat et al., 2020; Fatehi et al., 2005; Lazavi et al., 2018; lloon Kashkooli et al., 2015; Mohammadi et al., 2014; Mohammadi et al., 2011; Shidfar et al., 2012; Taheri et al., 2012; Vrzal et al., 2005). The antioxidant activity 
of the Berberis vulgaris and its content in berberine and polyphenolic compounds can reduce lipid peroxidation, improve lipid profile, liver function, and acid secretion (Firouzi et al., 2018; Lazavi et al., 2018).

Table 4. Levels of lipid profile in all experimental groups (all $n=8)$.

\begin{tabular}{|c|c|c|c|c|c|}
\hline Group & Cholesterol & ucose & Triglycerides & $\mathrm{DL}$ & $\mathrm{DL}$ \\
\hline & 5 & $92,3,4$ & & $88 \pm 3.48$ & $40 \pm 4$ \\
\hline & & & & & \\
\hline \multirow[t]{3}{*}{ (Control) } & & & & 10.05 & 37.45 \\
\hline & & & & 79 & IQR \\
\hline & 6,7 & (4),5,5, & & $35^{*}$ & $4^{(3), 4,4,6,6,7}$ \\
\hline 2 & .04] & $4.62]$ & 2 & 42.77] & [21.91-30.85] \\
\hline \multirow[t]{2}{*}{ (Hyper) } & $\begin{array}{l}\text { Median: } 100.50 \\
\text { IOR. } 7700\end{array}$ & $\begin{array}{l}\text { Median: } 206.50 \\
\text { IOR. } 5800\end{array}$ & $\begin{array}{l}\text { Median: } 110.50 \\
\text { IOR. } 1650\end{array}$ & $\begin{array}{l}36.40 \\
8 .\end{array}$ & $\begin{array}{l}\text { Median: } 27.55 \\
\text { IQR } 988\end{array}$ \\
\hline & 356,7 & $.34^{(7)}$ & 74 & 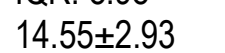 & $48^{(5),(7)}$ \\
\hline 3 & {$[7$} & 6] & 91] & 01] & {$[30$.} \\
\hline \multirow[t]{2}{*}{ (AE) } & $\begin{array}{l}\text { Median: } 81.50 \\
\text { IQR: } 13.50\end{array}$ & $\begin{array}{l}56.00 \\
0\end{array}$ & $\begin{array}{l}\text { dian: } 77.00 \\
\text { R: } 28.50\end{array}$ & $\begin{array}{l}\text { Median: } 14.43 \\
\text { IQR: } 2.72\end{array}$ & $\begin{array}{l}\text { Median: } 31.75 \\
\text { IQR: } 6.47\end{array}$ \\
\hline & $696,(7)$ & 162.8 & 68.87 & 15.4 & 36. \\
\hline \multirow{3}{*}{$\begin{array}{c}4 \\
\text { (RE) }\end{array}$} & {$[68$.} & {$[140$} & {$[59.2$} & {$[13$} & {$[32.5$} \\
\hline & Median: 79.50 & Median: & Median: 68.00 & $: 15.80$ & $\begin{array}{l}\text { Median: } 36.15 \\
\text { OQR } 5.97\end{array}$ \\
\hline & & 51 & & & \\
\hline 5 & {$[62.00$} & {$[117$.} & {$[59.3$} & {$[12$.} & {$[30.87$} \\
\hline \multirow[t]{3}{*}{ (Berberis) } & Median: 72.00 & Median: 147.50 & Median: 74.50 & Median: 14.25 & Median: 38.80 \\
\hline & & ID. & & & . \\
\hline & & $149.25 \pm 17.54$ & $66.62 \pm 11.09$ & $12.51 \pm 2.68$ & $34.53 \pm 2.88$ \\
\hline \multirow{3}{*}{$\begin{array}{c}6 \\
\text { (BAE) }\end{array}$} & {$[43.22-57.02$} & [134.57-163.92] & [57.34-75.90] & {$[10.27$} & [32.12-36.94] \\
\hline & lian: 48.50 & 54.00 & 66.50 & 12.95 & Median: 35.20 \\
\hline & & 13 & 70 & 12.7 & 382 \\
\hline \multirow{3}{*}{$\begin{array}{c}7 \\
\text { (BRE) }\end{array}$} & & $4]$ & [57.24-84.00] & [3.86] & [32.95-43.54] \\
\hline & Media & Median: 130.00 & Median: 64.00 & Median: 12.70 & Median: 36.45 \\
\hline & IQR: 16.00 & IQR: 9.50 & IQR: 32.25 & IQR: 1.12 & IQR: 9.85 \\
\hline
\end{tabular}

Data are presented as mean \pm standard deviation and $95 \%$ confidence interval for the mean [lower bound-upper bound]; median and interquartile range $(I Q R)$ are also displayed for the non-normal variables. Being *: significant difference $(p<.05)$ with all the rest of the groups; 1,2,3,4,5,6,7: significant difference with the group 1, 2, 3, 4, 5, 6, or 7, respectively (numbers between brackets represent statistical tendency at the level $0.5<p<1.3$ ); IQR: interquartile range; Hyper: hypercaloric group; AE: aerobic exercise group; RE: resistance exercise group; BAE: black Berberis vulgaris extract intake in combination with aerobic exercise; BRE: black Berberis vulgaris extract intake in combination with resistance exercise; AST: aspartate aminotransferase (also known as GOT); ALT: alanine aminotransferase (also known as GPT); CRP: C-reactive protein.

The usefulness of combining this nutritional supplement with physical exercise is supported by the results of our study, with significant differences (slightly better results for the combination of the extract and both exercise methodologies) or tendencies in the ALT, CRP, urea, cholesterol, glucose, and HDL (see Tables 3 and 4). Also, several previous studies have reported a beneficial effect on weight loss, NAFLD, and CVD after taking Berberis vulgaris and performing aerobic and resistance training (Schroeder et al., 2019; Torkamaneh et al., 2016). It has been also reported that regular aerobic exercise improves the lipid profile (Ghanbari et al., 2007; Kazeminasab et al., 2013; Kraus et al., 2002; LeMura et al., 2000). Regular aerobic or resistance training with caloric restriction is a common therapy to control obesity. Although the specific mechanisms of the exercise-induced improvement in the lipid profile remain unclear, previous research 
suggests that it is due to an increase in lipid consumption (Earnest et al., 2013; Wang \& Xu, 2017). One possible mechanism is the increased activity of lipoprotein lipase (LPL), which is responsible for the hydrolysis of fasting triacylglycerol, ultra-low-density lipoproteins (chylomicrons), and very-low-density lipoprotein (Calabresi et al., 2010; Miyasita et al., 2010). Exercise can strongly develop plasma LPL activity, which promotes LPL-mediated triglycerides hydrolysis and therefore, improves the lipid profile (Kobayashi et al., 2007; Miyashita et al., 2010; Wang \& Xu, 2017). Another mechanism underlying the beneficial effects of regular exercise is related to fat utilization through increased lipid oxidation during exercise (Matsuura et al., 2001).

Taken together, all the outcomes of this research suggest that restricting the calories to a normocaloric diet, altogether with the use of Berberis vulgaris extract and/or with aerobic and resistance training may be effective in the treatment of CVD and also NAFLD. Both treatments (exercise and Berberis extract) proved useful in improving the assessed parameters, however, their combination resulted in slightly better values.

\section{CONCLUSION}

In conclusion, regular exercise (aerobic and/or resistance) and Berberis vulgaris extract intake can reduce blood lipid profile, metabolic parameters, and liver enzymes in rats with diet-induced obesity. In the present study, the best results were obtained by combining Berberis Vulgaris $L$ with aerobic or resistance training. Thus, regular aerobic or resistance training in combination with the intake of Berberis vulgaris may have a positive effect on certain risk factors to cardiovascular and fatty liver disease, such as hyperlipidemia and obesity.

\section{ACKNOWLEDGMENT}

The authors gratefully acknowledge the cooperation of the Shahrekord Medicinal Plants Research Center, which supported and funded this project. We would also like to thank all the research staff members who participated in the present study.

\section{REFERENCES}

Aslani, N., Entezari, M. H., Askari, G., Maghsoudi, Z., \& Maracy, M. R. (2016). Effect of garlic and lemon juice mixture on lipid profile and some cardiovascular risk factors in people 30-60 years old with moderate hyperlipidaemia: a randomized clinical trial. International Journal of Preventive Medicine, 7(1), 95. https://doi.org/10.4103/2008-7802.187248

Atkins, J. L., Whincup, P. H., Morris, R. W., Lennon, L. T., Papacosta, O., \& Wannamethee, S. G. (2014). Sarcopenic obesity and risk of cardiovascular disease and mortality: a population-based cohort study of older men. Journal of the American Geriatrics Society, 62(2), 253-260. https://doi.org/10.1111/jgs.12652

Bernhardt, V., Stickford, J. L., Bhammar, D. M., \& Babb, T. G. (2016). Aerobic exercise training without weight loss reduces dyspnea on exertion in obese women. Respiratory Physiology \& Neurobiology, 221, 64-70. https://doi.org/10.1016/j.resp.2015.11.004

Calabresi, L., \& Franceschini, G. (2010). Lecithin: cholesterol acyltransferase, high-density lipoproteins, and atheroprotection in humans. Trends in Cardiovascular Medicine, 20(2), 50-53. https://doi.org/10.1016/i.tcm.2010.03.007

Cao, H., Li, C., Lei, L., Wang, X., Liu, S., Liu, Q., Huan, Y., Sun, S., \& Shen, Z. (2020). Stachyose improves the effects of berberine on glucose metabolism by regulating intestinal microbiota and 
short-chain fatty acids in spontaneous type 2 diabetic KKAy Mice. Frontiers in Pharmacology, 11, 1641. https://doi.org/10.3389/fphar.2020.578943

Changizi Ashtiyani, S., Zarei, A., Taheri, S., Rezaei, A., Golshan, M., \& Ghafarzadegan, R. (2013). A comparative study of hypolipidemic activities of the extracts of Melissa officinalis and Berberis vulgaris in rats. Journal of Medicinal Plants, 12(47), 38-47.

Dulić, M., Ciganović, P., Vujić, L., \& Zovko Končić, M. (2019). Antidiabetic and cosmeceutical potential of common barbery (Berberis vulgaris $L$ ) root bark extracts obtained by optimization of 'Green' ultrasound-assisted extraction. $\quad$ Molecules, 3613. https://doi.org/10.3390/molecules24193613

Earnest, C. P., Artero, E. G., Sui, X., et al. (2013). Maximal estimated cardiorespiratory fitness, cardiometabolic risk factors, and metabolic syndrome in the aerobics center longitudinal study. In Mayo Clinic Proceedings, 88(3), 259-270). https://doi.org/10.1016/..mayocp.2012.11.006

Emamat, H., Zahedmehr, A., Asadian, S., Tangestani, H., \& Nasrollahzadeh, J. (2020). Effect of barberry (Berberis vulgaris) consumption on blood pressure, plasma lipids, and inflammation in patients with hypertension and other cardiovascular risk factors: study protocol for a randomized clinical trial. Trials, 21(1), 1-9. https://doi.org/10.1186/s13063-020-04918-7

Fatehi-Hassanabad, Z., Jafarzadeh, M., Tarhini, A., \& Fatehi, M. (2005). The antihypertensive and vasodilator effects of aqueous extract from Berberis vulgaris fruit on hypertensive rats. Phytother Research: An International Journal Devoted to Pharmacological and Toxicological Evaluation of Natural Product Derivatives, 19(3), 222-225. https://doi.org/10.1002/ptr.1661

Firouzi, S., Malekahmadi, M., Ghayour-Mobarhan, M., Ferns, G., \& Rahimi, H. R. (2018). Barberry in the treatment of obesity and metabolic syndrome: possible mechanisms of action. Diabetes, Metabolic Syndrome and Obesity: Targets and Therapy, 11, 699-705. https://doi.org/10.2147/DMSO.S181572

Ghanbari-Niaki, A., Khabazian, B. M., Hossaini-Kakhak, S. A., et al. (2007). Treadmill exercise enhances ABCA1 expression in rat liver. Biochemical and Biophysical Research Communications, 361(4), 841846. https://doi.org/10.1016/i.bbrc.2007.07.100

Haselgrübler, R., Lanzerstorfer, P., Röhrl, C., et al. (2019). Hypolipidemic effects of herbal extracts by reduction of adipocyte differentiation, intracellular neutral lipid content, lipolysis, fatty acid exchange and lipid droplet motility. Scientific Reports, 9(1), 1-18. https://doi.org/10.1038/s41598-019-47060-4

Iloon Kashkooli, R., Najafi, S. S., Sharif, F., Hamedi, A., Hoseini Asl, M. K., Najafi Kalyani, M., \& Birjandi M. (2015). The effect of Berberis vulgaris extract on transaminase activities in non-alcoholic fatty liver disease. Hepatitis Monthly, 15(2), https://doi.org/10.5812/hepatmon.25067

Imenshahidi, M. \& Hosseinzadeh, H. (2019). Berberine and barberry (Berberis vulgaris): a clinical review. Phytotherapy Research, 33(3), 504-523. https://doi.org/10.1002/ptr.6252

Kamada, M., Shiroma, E. J., Buring, J. E., Miyachi, M., \& Lee, I. M. (2017). Strength training and allcause, cardiovascular disease, and cancer mortality in older women: a cohort study. Journal of the American Heart Association, 6(11), e007677. https://doi.org/10.1161/JAHA.117.007677

Kang, J. G. \& Park., C.-Y. (2012). Anti-obesity drugs: a review about their effects and safety. Diabetes \& Metabolism Journal, 36(1), 13-25. https://doi.org/10.4093/dmi.2012.36.1.13

Kazeminasab, F., Marandi, M., Ghaedi K., Esfarjani, F., \& Moshtaghian, J. (2013). Endurance training enhances LXRa gene expression in Wistar male rats. European Journal of Applied Physiology, 113(9), 2285-2290. https://doi.org/10.1007/s00421-013-2658-z

Kobayashi, J., Nohara, A., Kawashiri, M., Inazuc, A., Koizumid, J., Nakajimae, K., \& Mabuchia, H. (2007). Serum lipoprotein lipase mass: clinical significance of its measurement. Clinica Chimica Acta, 378(12), 7-12. https://doi.org/10.1016/i.cca.2006.12.003 
Kraus, W., Houmard, J., Duscha B., et al. (2002). Effects of the amount and intensity of exercise on plasma lipoproteins. New England Journal of Medicine, 347(19), 1483-1492. https://doi.org/10.1056/NEJMoa020194

Lazavi, F., Mirmiran, P., Sohrab, G., Nikpayam, O., Angoorani, P., \& Hedayati, M. (2018). The barberry juice effects on metabolic factors and oxidative stress in patients with type 2 diabetes: a randomized clinical trial. Complementary Therapies in Clinal Practice, 31, 170-174. https://doi.org/10.1016/i.ctcp.2018.01.009

LeMura, L., von Duvillard, S., Andreacci, J., Klebez, J. M., Chelland. S. A., \& Russo J. (2000). Lipid and lipoprotein profiles, cadiovascular fitness, body composition, and diet during and after resistance, aerobic and combination training in young women. European Journal of Applied Physiology, 82(56), 451-458. https://doi.org/10.1007/s004210000234

Liu, Y., Lee, D. C., Li, Y., et al. (2019). Associations of resistance exercise with cardiovascular disease morbidity and mortality. Medicine and science in sports and exercise, 51(3), 499. https://doi.org/10.1249/MSS.0000000000001822

MacDonald, H. V., Johnson, B. T., Huedo-Medina, T. B., et al. (2016). Dynamic resistance training as stand-alone antihypertensive lifestyle therapy: a meta-analysis. Journal of the American Heart Association, 5(10), e003231. https://doi.org/10.1161/JAHA.116.003231

Maliakkal, B. J. (2020). Pathogenesis of non-alcoholic fatty liver disease and implications on cardiovascular outcomes in liver transplantation. Translational Gastroenterology and Hepatology, 5, 36. https://doi.org/10.21037/tgh.2019.12.02

Matsuura, H. (2001). Saponins in garlic as modifiers of the risk of cardiovascular disease. The Journal of Nutrition, 131(3), 1000S-1005S. https://doi.org/10.1093/in/131.3.1000S

Mazidi, M. \& Speakman, J. R. (2018). Impact of obesity and ozone on the association between particulate air pollution and cardiovascular disease and stroke mortality among US adults. Journal of the American Heart Association, 7(11), e008006. https://doi.org/10.1161/JAHA.117.008006

Miyachi, M. (2013). Effects of resistance training on arterial stiffness: a meta-analysis. British Journal of Sports Medicine, 47(6), 393-396. https://doi.org/10.1136/bjsports-2012-090488

Miyashita, M., Eto, M., Sasai, H., Tsujimoto, T., Nomata, Y., \& Tanaka, K. (2010). Twelve-week jogging training increases pre-heparin serum lipoprotein lipase concentrations in overweight/obese middleaged men. Journal of Atherosclerosis and Thrombosis, 17(1), 21-29. https://doi.org/10.5551/jat.2337

Mohammadi, A., Sahebkar, A., Kermani, T., Zhilaee, M., Tavallaie, S., \& Ghayour Mobarhan, M. (2014). Barberry administration and pro-oxidant-antioxidant balance in patients with metabolic syndrome. Iranian Red Crescent Medical Journal, 16(12), e16786. https://doi.org/10.5812/ircmj.16786

Mohammadi, M., Bagheri, A., Marashi, H., Moshtaghi, N., \& Balandari, A. (2011). Investigation into seasonal effect and browning inhibitor on callus regeneration of seedless barberry (Berberis vulgaris var. asperma). Plant Tissue Culture and Biotechnology, 21(2), 161-168. https://doi.org/10.3329/ptcb.v21i2.10239

Schroeder, E. C., Franke, W. D., Sharp, R. L., \& Lee, D. (2019). Comparative effectiveness of aerobic, resistance, and combined training on cardiovascular disease risk factors: a randomized controlled trial. PloS One, 14(1), e0210292. https://doi.org/10.1371/journal.pone.0210292

Shamsoddini, A., Sobhani, V., Ghamar Chehreh, M. E., Alavian, S. M., \& Zaree, A. (2015). Effect of aerobic and resistance exercise training on liver enzymes and hepatic fat in Iranian men with nonalcoholic fatty liver disease. Hepatitis Monthly, 15(10), e31434. https://doi.org/10.5812/hepatmon.31434

Shidfar, F., Ebrahimi, SS., Hosseini, S., Heydari, I., Shidfar, S., \& Hajhassani, G. (2012). The effects of Berberis vulgaris fruit extract on serum lipoproteins, apoB, apoA-I, homocysteine, glycemic control 
and total antioxidant capacity in type 2 diabetic patients. Iranian Journal of Pharmaceutical Research, 11(2), 643-652.

Tabeshpour, J., Imenshahidi, M., \& Hosseinzadeh, H. (2017). A review of the effects of Berberis vulgaris and its major component, berberine, in metabolic syndrome. Iranian Journal of Basic Medical Sciences, 20(5), 557-568.

Taheri, S., Zarei, A., Ashtiyani, S. C., Rezaei, A., \& Zaheiri, S. (2012). Evaluation of the effects of hydroalcoholic extract of berberis vulgaris root on the activity of liver enzymes in male hypercholesterolemic rats. Avicenna Journal of Phytomedicine, 2(3), 153.

Torkamaneh, S., Sharifi, GH., \& Rafieian, M. (2016). The comparison between the effects of Berberis vulgaris Extract and aerobic exercise on none-alcoholic fatty liver in male rats. Der Pharma Chemica, $8(1), 244-247$.

Vrzal, R., Zdařilová, A., Ulrichová, J., Bláha, L., Giesy, J. P., \& Dvořák, Z. (2005). Activation of the aryl hydrocarbon receptor by berberine in HepG2 and H4IIE cells: biphasic effect on CYP1A1. Biochemical Pharmacology, 70(6), 925-936. https://doi.org/10.1016/i.bcp.2005.06.016

Wang, Y., \& Xu, D. (2017). Effects of aerobic exercise on lipids and lipoproteins. Lipids in Health and Disease, 16(1), 1-8. https://doi.org/10.1186/s12944-017-0515-5

Wood, P. D., Stefanick, M. L., Williams, P. T., \& Haskell, W. L. (1991). The effects on plasma lipoproteins of a prudent weight-reducing diet, with or without exercise, in overweight men and women. New England Journal of Medicine, 325(7), 461-466. https://doi.org/10.1056/NEJM199108153250703

World Health Organization (2017). Global recommendations on physical activity for health. ISBN: 9789241599979. Retrieved from: $h$ htps://www.who.int/publications/litem/9789241599979

Yang, Y., Chan, S. W., Hu, M., Walden, R., \& Tomlinson, B. (2011). Effects of some common food constituents on cardiovascular disease. ISRN Cardiology, 2011, 397136. https://doi.org/10.5402/2011/397136

Yang, Z., Scott, C. A., Mao, C., Tang, J., \& Farmer, A. J. (2014). Resistance exercise versus aerobic exercise for type 2 diabetes: a systematic review and meta-analysis. Sports Medicine, 44(4), 487499. https://doi.org/10.1007/s40279-013-0128-8

Zarei, A., Changizi-Ashtiyani, S., Taheri, S., \& Ramezani, M. (2015). A quick overview on some aspects of endocrinological and therapeutic effects of Berberis vulgaris L. Avicenna Journal of Phytomedicine, 5 (6), 485-497.

Zhan, J., Liu, Y. J., Cai, L. B., Xu, F. R., Xie, T., \& He, Q. Q. (2017). Fruit and vegetable consumption and risk of cardiovascular disease: a meta-analysis of prospective cohort studies. Critical Reviews in Food Science and Nutrition, 57(8), 1650-1663. https://doi.org/10.1080/10408398.2015.1008980

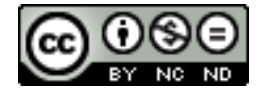

This work is licensed under a Attribution-NonCommercial-NoDerivatives 4.0 International (CC BY-NC-ND 4.0). 